\title{
Importance of Pits in Corymbia Citriodora (Hook.) K.D. Hill \& L.A.S. Johnson (Myrtaceae) Wood Permeability
}

\author{
Thiago Campos Monteiro ${ }^{1}$ \\ José Tarcísio Lima² ${ }^{2}$ \\ Raul Abreu Neto ${ }^{2}$ (1) \\ Cassiana Alves Ferreira ${ }^{2}$ (1)
}

\begin{abstract}
Aim of this research was to evaluate the relationship between the biometrics of vessel-ray pits (RVP) and intervessel pits (IVP) with the water flow in different axes of Corymbia citriodora wood. C. citriodora wood specimens were used to correlate RVP and IVP dimensions with free water (FWFR), adsorbed (AWFR) and total (TWFR) flow. Correlations were made for three wood axes. Larger diameters of RVP facilitated FWFR, AWFR and TWFR in axial and tangential axis, however reduced permeability in radial direction of wood. Larger openings of IVPs reduced FWFR, AWFR and TWFR in axial axis of wood. Larger IVPs openings allowed higher FWFR and TWFR in wood radial and tangential directions, however, concomitantly reduced AWR. Effect of diameter of RVP and IVP on wood permeability should be evaluated for each axis. Thus, the opening of the C. citriodora wood pits can interfere in its permeability and consequently in its processing.
\end{abstract}

Keywords: Free water, Adsorbed water, Drying, Vessel-Ray Pit, Intervessel pits.

\section{INTRODUCTION}

Moving of water inside the wood has been scientifically study for centuries. Water in wood can be found, basically as free water and bound water (Siau, 1984; Engelund et al., 2013), with both types exhibiting different behaviour and distinct drying times (Monteiro et al., 2018, 2020). According to Engelund et al. (2013), studies on water interactions in wood have conifer species as the main focus. In recent years, Brazilian researchers conducted studies dedicated especially to species of the Myrtaceae family and the genus Corymbia (Eleoterio et al., 2015; Monteiro et al., 2018, 2020; Loureiro et al., 2019).

It is known that fibers, vessels, radial and axial parenchyma cells make C. citriodora wood porous. The passage of fluids through these structures is complex, as it occurs with water in both the liquid and gaseous phases (Siau, 1984). This movement of water in the hardwood stem occurs mainly through vessels and pairs of pits (Siau, 1984; Engelund et al., 2013; Monteiro \& Lima, 2020). Permeability techniques were able to obtain the flow only on the axial axis, when analysing the different axes of the wood, the complexity of the water flow increases considerably (Baraúna et al., 2014; Zanuncio et al., 2016; Rezende et al., 2018).

There are few studies that have addressed in detail the movement of free and adsorbed water, in addition to the axes, during drying in hardwood, mainly of the genus Corymbia. Knowledge about the effect of vascular and intervessel pits of hardwood on water flow is important for the optimization of industrial drying of this wood,

${ }^{1}$ Universidade Federal do Paraná, Departamento de Engenharia e Tecnologia Florestal, Curitiba, PR, Brasil

${ }^{2}$ Universidade Federal de Lavras, Departamento de Ciências Florestais, Lavras, MG, Brasil 
especially when the few reports focus on the importance of vases, rays and cell walls (Siau, 1984; Zanuncio et al., 2016; Monteiro et al., 2018). Different situation occurs with coniferous wood, which the importance of bordered pits in water movement has been widely reported in several studies (Engelund et al., 2013; Sakagami et al., 2016; Panigrahi et al., 2018).

To our knowledge, there is little information concerning the relationship between wood permeability and pits according to the wood axes, especially in Corymbia. Thus, the aim of this study was to evaluate the relationship between the biometrics of vessel-ray pits and intervessel pits with the water flow in different axes of Corymbia citriodora wood.

\section{MATERIAL AND METHODS}

\subsection{Material selection and preparation}

Three Corymbia citriodora trees provided by Cenibra company, in Belo Oriente, Minas Gerais State, Brazil, were used. The selected trees were cut at seven years of age and they possibly had only juvenile wood (Palermo et al. 2015). The planting conducted with a spacing of $3 \times 3 \mathrm{~m}$ between trees. One central board of each first log was produced and two wooden scantlings were cut from opposite sides. Each piece was removed from the central region between the pith and the bark.

Four cubic specimens with $30 \mathrm{~mm}$ sides were produced from each batten at Wood Machining Laboratory of Federal University of Lavras (UFLA), Lavras city, Minas Gerais State, Brazil. The specimen in middle position of stick (from a tree height of approximately $1.3 \mathrm{~m}$ from the soil) was removed to determine the pits diameter. Others remaining specimens were divided in half, according to the orientation of the drying axis, with dimensions equal to $30 \times 30 \times 15 \mathrm{~mm}$, according to the methodology adopted by Monteiro et al. (2020). The axis with the smallest dimension was used to evaluate water flow, in the axial, radial, and tangential axes. The other corners of the sample were waterproofed to force drying only in the direction evaluated.

\subsection{Water flow evaluation and pits measurement}

Tests were conducted at UFLA Physical and Mechanical Properties of Wood Laboratory. 12 specimens per tree (four for each drying axis) were placed in an air-conditioned room with a temperature of $20 \pm 2^{\circ} \mathrm{C}$ and relative humidity equal to
$65 \pm 5 \%$. The loss of mass was performed for 75 days, until a constant mass was obtained. Measurements were performed on a digital electronic scale, accurate to $0.01 \mathrm{~g}$, every $6 \mathrm{~h}$ in the first week, every $12 \mathrm{~h}$ in the second week and every $24 \mathrm{~h}$ until the masses stabilize. After this time, the specimens were taken to an oven with a temperature of $103 \pm 2^{\circ} \mathrm{C}$, and dried until constant mass.

After monitoring the drying of specimens and obtaining the drying times and moisture content, the free water flow rates (FWFR), adsorbed water (AWFR) and total water (TWFR) of C. citriodora wood were estimated, considering different axes of wood, according to the methodology adopted by Monteiro et al. (2020).

Measurement of diameters of vessel-ray pits (VPR) and intervessel pits (IVP) were performed in the six intermediate specimens of each batten. The measurements were taken, in the Electronic Microscopy Laboratory. Specimen preparation and measurements were performed according to the adaptation of Alves et al. (2013).

A database with information on water flow rates and VRP and IVP was developed for each axis of wood. Correlations of diameters of the pits with drying rates were calculated and regression models were adjusted. The best models were selected based on coefficient of determination $\left(\mathrm{R}^{2}\right)$.

\section{RESULTS}

Data relating to models between vessel-ray pits (VRP) and intervessel pits (IVP) with the flow of free water rate, adsorbed water flow rate and total water flow rate in the three axes of wood are shown in Table 1. In the axial axis of the Corymbia wood, the opening of the vessel-ray pits (VRP) and intervessel pits (IVP) did not influence the flow of free water (FWFR). On the other hand, a direct and positive relationship was observed between total drying (TWFR) and opening of the VRP. Likewise, but with an inversely proportional behaviour, the opening of the IVP reduced the flow of adsorbed water (AWFR). In the wood radial direction, in general the VRP presented inversely proportional relation with the three water flows and the IVP presented an inverse behaviour for FWFR and TWFR. In the wood tangential axis, the largest $\mathrm{R}^{2}$ were for AWFR, with directly proportional relationship with the VRP and inversely proportional with the IVP.

Vessel-ray pits and intervessel pits of Corymbia citriodora wood are shown in Figure 1. Figure 1A showed the one opening of the pit connecting the vessel element and the ray parenchyma cell. Connecting other structures, Figure 1B showed the pits between the vessel elements. 
Table 1. Correlation models between drying rates in the different axes of Corymbia citriodora wood and diameter of vascular and intervessel pit.

\begin{tabular}{|c|c|c|c|c|}
\hline Wood axes & Vessel-ray pits & $\mathbf{R}^{2}$ & Intervessel pits & $\mathbf{R}^{2}$ \\
\hline \multirow{3}{*}{ Axial } & $\mathrm{FWFR}=0.0005 \mathrm{VRP}+0.0054$ & 0.06 & FWFR $=-0.0006 \mathrm{IVP}+0.0092$ & 0.02 \\
\hline & $\mathrm{AWFR}=7 \mathrm{E}-05 \mathrm{VRP}+0.0004$ & 0.19 & AWFR $=-0.0006 \mathrm{IVP}+0.0019$ & 0.64 \\
\hline & $\mathrm{TWFR}=0.0022 \mathrm{VRP}-0.0078$ & 0.48 & TWFR $=-0.0009 \mathrm{IVP}+0.0038$ & 0.31 \\
\hline \multirow{3}{*}{ Radial } & $F W F R=-0.01 V R P+0.0486$ & 0.36 & $F W F R=0.0018 I V P+0.0003$ & 0.96 \\
\hline & AWFR $=-0.0003 \mathrm{VRP}+0.0015$ & 0.02 & AWFR $=-0.0003 \mathrm{IVP}+0.0009$ & 0.64 \\
\hline & $\mathrm{TWFR}=-0.0032 \mathrm{VRP}+0.0153$ & 0.83 & $\mathrm{TWFR}=0.0002 \mathrm{IVP}+0.0006$ & 0.40 \\
\hline \multirow{3}{*}{ Tangential } & $\mathrm{FWFR}=0.003 \mathrm{VRP}-0.0112$ & 0.20 & $\mathrm{FWFR}=0.0017 \mathrm{IVP}-0.0014$ & 0.31 \\
\hline & $\mathrm{AWFR}=0.0006 \mathrm{VRP}-0.0025$ & 0.86 & $\mathrm{AWFR}=-0.0002 \mathrm{IVP}+0.0008$ & 0.60 \\
\hline & TWFR $=0.0004 \mathrm{VRP}-0.0009$ & 0.15 & TWFR $=0.0001 \mathrm{IVP}+0.0006$ & 0.48 \\
\hline
\end{tabular}

Where: $\mathrm{R}^{2}$ : coefficient of determination; FWFR: free water flow rate; AWFR: adsorbed water flow rate; TWFR: total water flow rate; VRP: diameter of the vessel-ray pits; IVP: diameter of intervessel pits.
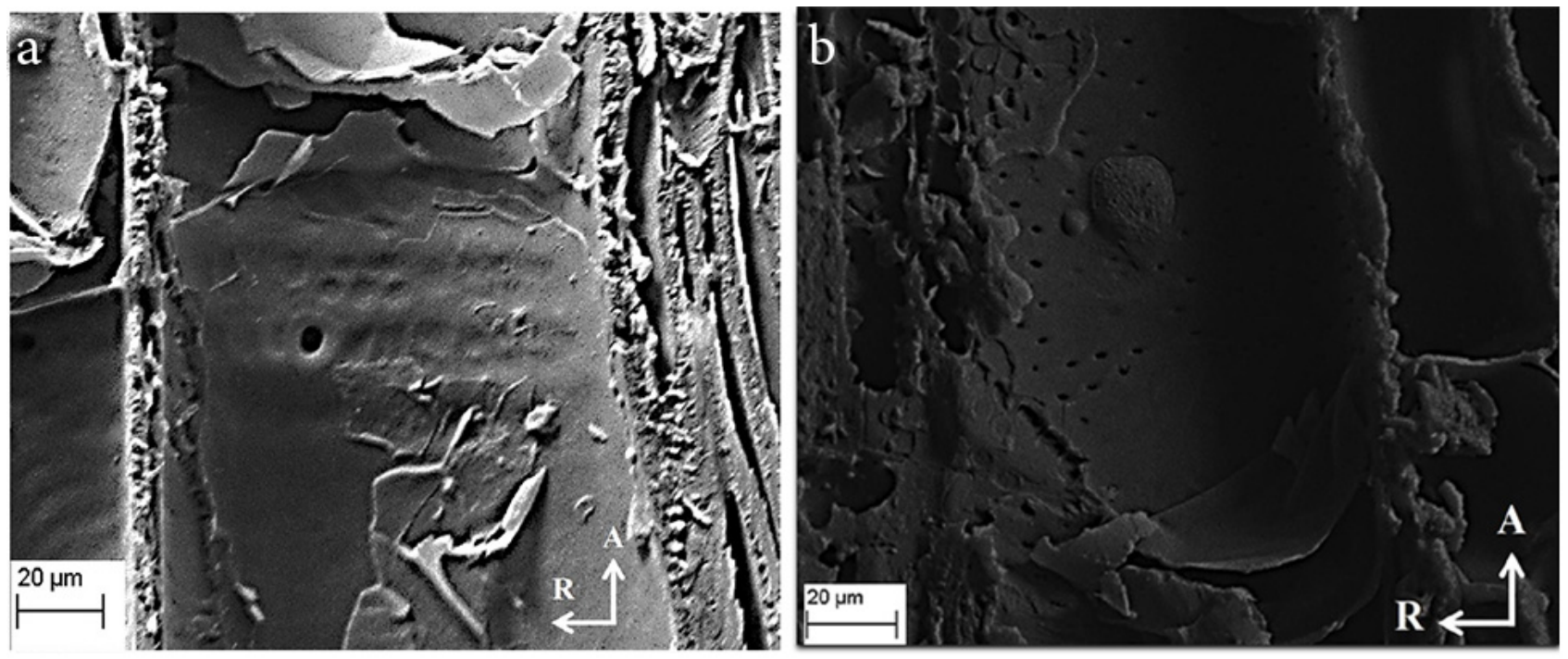

Figure 1. Pits in Corymbia citriodora wood. A - vessel ray; B - intervessel.

\section{DISCUSSION}

The largest opening of vessel-ray pits (VPR) favoured the movement of free water flow rates (FWFR), adsorbed water (AWFR) and total water (TWFR) in axial and tangential axis of Corymbia citriodora wood (Table 1). TWFR in axial axis and AWFR in tangential direction showed the best determination coefficients $\left(\mathrm{R}^{2}\right)$. These results demonstrate that the VPR positively help water flow in longitudinal and tangential direction of wood. However, the opposite behaviour occurred in radial direction, when the increase in the opening of VPR reduced the flow of water in this direction, mainly for the FWFR and TWFR of wood.

It is important to consider that VRP (Figure 1A) occurs between a cell of ray parenchyma and another of vessel, which is the main element responsible for the flow of water into hardwoods (Siau, 1984; Kedrov, 2012; Engelund et al., 2013). It is noted in the behaviour presented in Table 1 that VRP ended up favouring flow of water even more in longitudinal direction, possibly assisting in the function of vessels. The importance of VRP in movement of water in wood is reported in several studies (Siau, 1984; Engelund et al., 2013; Monteiro \& Lima, 2020). The opening of VRP in Corymbia wood presents a similar behaviour of free and adsorbed water flow to the flow in the axial and radial axes when compared with Eucalyptus wood (Monteiro \& Lima, 2020). On the other hand, the same study shows an inverse behaviour for the flow of free water on the tangential axis of Eucalyptus wood.

The water permeability on the wood tangential axis is complex, mainly due to the absence of anatomical structures 
that favours its flow. Thus, flow of water in tangential direction of wood was possibly favoured by presence of VRP due to the lack of proper anatomical structures that stimulate the flow of water in this direction. Different from the axial and radial axes of wood, which have the vessels and rays, respectively to assist in the flow of water. Thus, in the tangential direction, the increase in VRP is important for greater water movement in C. citriodora wood. Kedrov (2012) reported similar behaviour, the author emphasized the importance of VRP in transversal movement of water in wood.

Alternatively, in the radial direction, the largest opening of VRP made the movement of water difficult (Table 1). Possibly the openings between the rays and vessels favoured the movement of water to vessel cavities and radial parenchyma, and due to the methodology used, with waterproofing of faces perpendicular to radial axis, water had more difficulty in moving in wood. The inversely proportional relationship between the opening of the VRP and the flow of free water in the radial direction of the wood was also found in Eucalyptus urophylla (Monteiro \& Lima, 2020).

Intervessel pit (IVP) has smaller openings, but more frequent when compared with VRP in C. citriodora wood (Figure 1B). The greater opening of IVP reduced the AWFR and TWFR in axial axis of C. citriodora wood (Table 1). On the other hand, in Eucalyptus wood, the relation to the free water flow was significant and inverse (positive) and did not affect the movement of the adsorbed water (Monteiro \& Lima, 2020). Possibly these openings favoured alternative paths for the flow of water, reducing flow in the vessels, the main structure responsible for permeability in the wood. In radial and tangential direction of wood, the largest openings of IVP allowed greater FWFR and TWFR. FWFR with IVP, in wood radial axis, presented $\mathrm{R}^{2}$ equal to 0.96 , the best correlation of the research. In radial and tangential axes of Eucalyptus urophylla wood, the same relationship was found, but with lower $\mathrm{R}^{2}$, with the opening of the IVP favouring the flow of free water and reducing the flow of adsorbed water (Monteiro \& Lima, 2020).

These results demonstrate the importance of IVP in drying of the faces and corners of boards or chips, as well as in rolling surface of C. citriodora logs (Table 1). The relevance of wood IVP in water flow is reported by Kedrov (2012), who presents as numerous pits and that tend to stay flat in their contact areas, to improve the water passage. The author also reports that the adjacent walls of IVP are clearly thicker than in other segments of the vascular element, possibly due to the fact that water penetrates the pits under pressure.

However, the opposite behaviour occurred with AWFR in radial and tangential direction of wood, when the increase in the opening of IVP reduced flow of water in these directions. These adjustments are possibly related to the diffusion of water in the cell wall of vessels. The openings of IVP serve as a discontinuity of cell wall, reducing the diffusion of water and facilitating the passage of liquid water and steam, which move mainly in moisture above the fiber saturation point (Kedrov, 2012; Engelund et al., 2013).

\section{CONCLUSIONS}

It can be concluded, with the evaluation of correlations between diameter of vessel-ray pit (VRP) and intervessel pit (IVP) points with the movement of free water (FWFR), adsorbed (AWFR) and total (TWFR), in the different axes of Corymbia citriodora wood, which:

- The largest openings of VRP facilitated FWFR, AWFR and TWFR on axial and tangential axis, otherwise reduced the flow of these waters in the radial direction of the wood.

- The highest values of IVP reduced FWFR, AWFR and TWFR in axial axis of Corymbia citriodora wood.

- In radial and tangential axes of $C$. citriodora wood the largest openings of IVP allowed greater FWFR and TWFR, however reduced AWFR.

- The vessel-ray and intervessel pits affected the permeability to the wood liquid. Consequently, these results are related to the drying of lumber, logs and chips, as well as being important in the impregnation with chemical reagents for the wood preservation and pulp.

\section{SUBMISSION STATUS}

Received: 30 Mar. 2020

Accepted: 10 Jul. 2020

Associate editor: João Vicente Latorraca (D)

\section{CORRESPONDENCE TO}

Thiago Campos Monteiro

Universidade Federal do Paraná (UFPR), Av. Pref. Lothário Meissner, 632 - Jardim Botânico, CEP: 80210-170, Curitiba, PR, Brasil e e-mail: thiago.monteiro@ufpr.br

\section{REFERENCES}

Alves E, Lucas GC, Pozza EA, Carvalho Alves M (2013) Scanning Electron Microscopy for Fungal Sample Examination. In: Laboratory Protocol in Fungal Biology - Currente Methods in Fungi Biology., Springer. New York, 2013.

Baraúna EEP, Lima JT, Vieira R da S, Silva JRM, Monteiro TC. Effect of anatomical and chemical structure in the permeability of 
“Amapá" wood. Cerne 2014; 20(4): 529-534. http://doi.org/10.159 0/01047760201420041501

Eleoterio JR, Bagattoli TR, Hornburg KF, Silva CMK. Secagem drástica de madeiras de Eucalyptus e Corymbia fornece informações para a elaboração de programas de secagem. Pesquisa Florestal Brasileira 2015; 35:451-547. http://doi.org/10.4336/2015.pfb.35.84.696

Engelund ET, Thygesen LG, Svensson S, Hill CAS. A critical discussion of the physics of wood-water interactions. Wood Science and Technology 2013; 47(1): 141-161. http://doi.org/10.1007/s00226-012-0514-7

Kedrov GB. Functioning wood. Wulfenia 2012; 19: 57-95.

Loureiro BA, Vieira TAS, Costa LJ, Silva AB, Assis, MR, Trugilho PF. Selection of superior clones of Corymbia hybrids based on wood and charcoal properties. Maderas. Ciencia y Tecnología 2019; 21:0-0. http://doi.org/10.4067/S0718-221X2019005000417

Monteiro TC, Lima JT. Water flow through the pits in Eucalyptus urophylla wood. Floresta e Ambiente 2020; 27(2): e20190092. http:// doi.org/10.1590/2179-8087.009219

Monteiro TC, Lima JT, Silva JRM, Rezende RN, Klitzke RJ. Water flow in different directions in Corymbia citriodora wood. Maderas. Ciencia y Tecnologia 2020; 22: ahead of print. http://dx.doi.org/10.4067/ S0718-221X2020005000312

Monteiro TC, Lima JT, Silva JRM, Zanuncio AJV, Baraúna EEP. Water flow evaluation in Eucalyptus and Corymbia short logs. Floresta e Ambiente 2018; 25(2): e20170659. http://doi. org/10.1590/2179 8087.065917

Palermo GP de M, Latorraca JV de F, Carvalho AM, Calonego FW, Severo ETD. Anatomical properties of Eucalyptus grandis wood and transition age between the juvenile and mature woods. European Journal of Wood and Wood Products 2015; 73: 775-780. http://doi.org/10.1007/s00107-015-0947-4

PanigrahiS, KumarS, PandaS, BorkatakiS.Effectofpermeabilityon primary processing of wood. Journal of Pharmacognosy and Phytochemistry 2018; 7: 2593-2598.

Rezende RN, Lima JT, Paula LER, Hein PRG, Silva JRM. Wood permeability in Eucalyptus grandis and Eucalyptus dunnii. Floresta e Ambiente 2018; 25(1): e20150228. http://doi. org/10.1590/2179 8087.022815

Sakagami H, Tokunaga A, Fujimoto N, Koga S, Kobayashi I, Momohara I. Effects of drying temperature for Cryptomeria japonica on the permeability of wood preservative I. The permeability of dried logs. BioResources 2016; 11: 4781-4793.

Siau JF. Transport processes in wood, Springer-V. New York. 1984.

Zanuncio AJV, Carvalho AG, Damásio RAP, Oliveira BS, Carneiro ACO, Colodette JL. Relationship between the anatomy and drying in Eucalyptus grandis $\mathrm{x}$ Eucalyptus urophylla wood. Revista Árvore 2016; 40(4): 723-729. http://dx.doi.org/10.1590/0100-67622016000400016. 